\title{
Investigation of male and female students' motivational characteristics throughout an introductory physics course sequence
}

\author{
Timothy J. Nokes-Malach ${ }^{1}$, Emily Marshman², Zeynep Y. Kalender ${ }^{2}$, Christian Schunn ${ }^{1}$, and Chandralekha Singh ${ }^{2}$ \\ ${ }^{1}$ Learning Research and Development Center, ${ }^{2}$ Department of Physics and Astronomy \\ University of Pittsburgh, Pittsburgh PA 15260
}

\begin{abstract}
Many hypotheses have been put forth regarding the reasons for the under-representation and under-performance of women in physics. While prior work has focused on the relations between students' prior knowledge and performance outcomes, less work has examined student motivation. To gain a better understanding of male and female students' motivational characteristics during instruction, we conducted a longitudinal study that evaluated students' self-efficacy, grit, fascination and value associated with physics, intelligence mindset, and physics epistemology at three points during two-semester introductory physics sequences. Females reported lower self-efficacy than males at the beginning of the year and those self-reports remained lower throughout the sequence. In addition, females' fascination and value associated with physics decreased more than those of males throughout the sequence. By the end of the sequence, females were also more likely than males to endorse the view that physics intelligence is a "fixed" ability. Implications for the design and implementation of effective instructional strategies are discussed.
\end{abstract}

\section{INTRODUCTION}

Research has shown that female students generally under-perform in introductory physics courses and only about $20 \%$ of physics majors are women [1,2]. Despite efforts to increase the number of women and reduce the performance gaps in physics courses, the underlying causes of the low representation and relatively poor performance of women are not well understood. Much work has focused on identifying cognitive factors related to poor performance. This research aims to improve learning outcomes through the development of pedagogies that build on students' prior knowledge and difficulties. Many of these strategies have been effective in improving students' physics knowledge and problem-solving skills [3]. However, it is unclear how these strategies impact women and whether they decrease performance gaps.

A complementary approach is to examine the role of student motivation during learning and instruction. For instance, prior work has shown that students' self-efficacy beliefs can affect their motivation to learn and, ultimately, learning outcomes in physics [4]. Self-efficacy can also influence choices to enroll in physics courses [5]. Therefore, investigating potential differences in males' and females' motivation and how that may change during the course of instruction may prove critical to understanding the performance gap. Here, we describe a study in which we assess a wide array of students' motivational characteristics at three points in time during a two-semester introductory physics course sequence. The findings have implications for the development and implementation of effective pedagogies to help all students learn.

\section{BACKGROUND}

Female students may underperform in physics courses and choose not to pursue a physics major or other majors requiring physics courses partly due to motivational characteristics. Below we describe several motivational characteristics that can impact students' engagement with instructional materials and learning in physics courses.

Studies have focused on students' interest and valuing of science, which are correlated with students' motivation during learning. Research suggests that interest in math and science is associated with the number of math and science courses taken in high school and career aspirations [5].

In addition to interest and value associated with physics, self-efficacy is another factor that can affect students' motivation to learn. Self-efficacy is the belief about one's capability to succeed on a particular task or in a specific situation. Research shows that apart from students' prior knowledge and skills, higher self-efficacy is positively correlated with expected grades in physics, enrollment in STEM courses, and career choices in STEM [6].

A student's grit is also associated with motivation and learning [7]. Grit is defined as one's perseverance and passion for long-term goals - a capacity to sustain both effort and interest in projects that take months or even longer to complete. It plays an important role for achieving success, even when controlling for students' prior knowledge [7]. To our knowledge, no studies of students' grit have been conducted in the context of introductory physics.

A student's intelligence mindset [8] refers to a set of beliefs about the nature of intelligence-an "entity theory" in which intelligence is viewed as a fixed trait that one is born with or an "incremental theory" in which intelligence is viewed as malleable and can be shaped by the environment. Students who have a malleable view of intelligence exhibit fewer negative emotions during academic challenges and put more effort to overcome the difficulties they face [8]. On the other hand, students with a fixed view of intelligence are 
concerned with demonstrating their intelligence and prefer tasks in which they feel capable and smart. When faced with difficult tasks, they tend to become debilitated and disengage. However, there have been few studies focusing on students' intelligence mindset in physics courses.

Similarly, students' epistemological beliefs about physics, i.e., their beliefs about what constitutes physics knowledge and how that knowledge is acquired, have been related to how they solve homework problems and study [9]. Students who have more "novice-like" epistemological beliefs tend to view physics as a collection of isolated facts and formulas and claim that learning physics involves receiving information as opposed to constructing their own understanding. Students who have these more novice like beliefs often use an algorithmic, as opposed to a systematic, approach in which they construct and re-organize their knowledge structures during problem solving and learning.

Since the motivational factors mentioned above can affect learning outcomes and there have been relatively few longitudinal studies focusing on these issues, we investigated male and female students' motivational characteristics throughout two introductory physics course sequences. The investigation can help determine the motivational factors for which there are differences between males and females and when those differences are present (e.g., at the beginning of a physics course sequence and/or later in the course sequence). The findings can be a stepping stone to developing and implementing better learning tools in order to help all students succeed in physics courses.

\section{METHODOLOGY}

Based upon our review of the motivation literature we selected six motivational constructs to assess. We then created a survey to cover the core aspects of each construct but with a goal to minimize total survey length, adapting questions from other well-validated surveys [7, 8, 10-15]. The final version of the survey has 29 Likert-scale items. See Table I for example survey items.

The survey was given to students at three points during two-semester introductory physics course sequences at a large research university in the U.S. Students in both algebrabased and calculus-based course sequences were asked to respond to survey questions at the beginning of Physics 1 in the fall semester 2015, the beginning of Physics 2 in the spring semester 2016, and also at the end of Physics 2 in the spring semester 2016. For the Physics 1 courses, a total of 3 instructors participated and students in 5 sections were given the survey. For the Physics 2 courses, a total of 4 instructors participated and students in 6 sections were given the survey. Physics 1 courses are composed of topics involving Newtonian mechanics whereas Physics 2 courses included topics related to electricity and magnetism. Students enrolled in the calculus-based physics courses are engineering or natural science majors, and students enrolled in the algebrabased courses intend to pursue careers in health or biological
TABLE I. Motivational factors with the number of items, example survey items, and scale.

\begin{tabular}{|c|c|c|}
\hline Factor & Example Survey Item & Scale \\
\hline $\begin{array}{l}\text { Fascination } \\
\text { with Physics } \\
3 \text { items }\end{array}$ & $\begin{array}{l}\text { I wonder about how nature } \\
\text { works ... }\end{array}$ & $\begin{array}{c}\text { Never } \\
\text { Once a month } \\
\text { Once a week } \\
\text { Every day }\end{array}$ \\
\hline $\begin{array}{l}\text { Valuing } \\
\text { Physics } \\
5 \text { items }\end{array}$ & $\begin{array}{l}\text { Knowing physics is important } \\
\text { for being a good citizen. }\end{array}$ & $\begin{array}{c}\text { No! } \\
\text { no } \\
\text { yes } \\
\text { Yes! }\end{array}$ \\
\hline $\begin{array}{l}\text { Self-Efficacy } \\
6 \text { items }\end{array}$ & $\begin{array}{l}\text { I am often able to help my } \\
\text { classmates with physics in the } \\
\text { laboratory or in recitation. }\end{array}$ & $\begin{array}{c}\text { No! } \\
\text { no } \\
\text { yes } \\
\text { Yes! }\end{array}$ \\
\hline $\begin{array}{l}\text { Intelligence } \\
\text { Mindset } \\
4 \text { items }\end{array}$ & $\begin{array}{l}\text {-You have a certain amount } \\
\text { of intelligence, and you can't } \\
\text { really do much to change it. } \\
\text {-Anyone can become good at } \\
\text { solving physics problems } \\
\text { through hard work. }\end{array}$ & $\begin{array}{l}\text { Strongly disagree } \\
\text { Disagree } \\
\text { Agree } \\
\text { Strongly agree }\end{array}$ \\
\hline $\begin{array}{c}\text { Grit } \\
3 \text { items }\end{array}$ & $\begin{array}{l}\text {-I often set a goal but later } \\
\text { choose to pursue a different } \\
\text { one. } \\
\text {-I finish whatever I begin. }\end{array}$ & $\begin{array}{l}\text { Not like me at all } \\
\text { Not much like me } \\
\text { Somewhat like me } \\
\text { Mostly like me } \\
\text { Very much like me }\end{array}$ \\
\hline \begin{tabular}{|c|} 
Physics \\
Epistemology \\
8 items
\end{tabular} & $\begin{array}{l}\text { I do not expect to understand } \\
\text { physics equations in an } \\
\text { intuitive sense; they must just } \\
\text { be taken as givens. }\end{array}$ & $\begin{array}{c}\text { Strongly disagree } \\
\text { Disagree } \\
\text { Agree } \\
\text { Strongly agree }\end{array}$ \\
\hline
\end{tabular}

science-related fields. The survey was administered in the first and the last recitation classes of the course in a written format. The survey was completed by most students in about 10-15 minutes.

For each survey item, students were given a score of 1-4 (or 5 for the questions related to grit). For the items related to fascination, value, grit, and self-efficacy, a high score means that a student is highly fascinated by physics, values physics highly, and has a high level of grit and self-efficacy. For the factor related to intelligence mindset, a high score means that a student has a malleable view of intelligence, whereas a low score means that a student views intelligence as a fixed ability. For physics epistemology, a high score means that a student has a more "expert-like" view of learning in physics, whereas a low score means that a student has a "novice-like" view. Each student was given an average score for each motivational factor. For example, a student who answered "Yes!" to three of the valuing physics questions and "no" to two of the valuing physics would have an average value score of $(4+4+4+2+2) /(5$ questions $)=3.2$.

At the beginning of fall 2015 and the beginning of spring 2016, we analyzed the internal consistency of the subscales, i.e., fascination, value, self-efficacy, intelligence mindset, grit, and physics epistemology. After the initial reliability analysis of the subscales in the fall 2015, we removed one of the statements in the grit subscale since the wording may have been confusing for students and it did not correlate well 
with other statements related to grit (the current version of the survey includes 3 grit items). After this revision, the survey was given again at the beginning of spring 2016. All Cronbach's alphas are above 0.60 which is considered fairly good, especially since some of the scales have only three items. The scales with five or more items all had a Cronbach's alpha of 0.70 or higher. No substantial increases in alpha for any of the scales could have been achieved by eliminating items.

To establish the separability of the different subscales along with validity of items as clear indicators of the scale to which they were assigned, we performed an exploratory factor analysis on the items in the survey based upon the data collected at the beginning of the spring 2016. A principal components analysis was used, and the initial eigenvalues indicated that the first six components explained a total of $49 \%$ of the variance (the $7^{\text {th }}$ component explained an additional $3.6 \%$ of the variance). The data supported the existence of six separable scales, and items loaded on the scales as intended.

We note that two of the items in the survey are related to "general" views about intelligence mindset, e.g., "You have a certain amount of intelligence, and you can't really do much to change it." However, the other two items related to intelligence mindset in the survey were embedded in a physics context, e.g., "Anyone can become good at solving physics problems through hard work." We postulated that males and females may answer questions related to "physics" intelligence mindset differently due to the stereotype that men perform better in logical, math-intensive fields and women perform better in communication and writingintensive field. Thus, in the results section, we report students" average "general" intelligence mindset and "physics" intelligence mindset separately.

\section{RESULTS}

We first report students' motivational characteristics at the beginning of Physics 1. We found that there were significant differences in the motivational characteristics of female and male students at the beginning of Physics 1 (see Table II for specific values of students' average motivational scores). In calculus-based physics, male students reported significantly higher values of self-efficacy, fascination, and value associated with physics. In algebra-based physics, male students reported significantly higher values of selfefficacy and fascination. On the other hand, females in algebra-based physics reported significantly higher levels of grit than males.

We also examined how students' motivational characteristics changed after taking a Physics 1 course focusing on Newtonian mechanics. We found that, on average, aspects of students' motivation generally decreased and the gaps between male and female students' motivational scores remained the same. However, in regards to fascination, we found that females' average reported
TABLE II. Female (F) and male (M) students' average motivational scores and Male > Female effect sizes (Cohen's d) at the beginning of calculus- and algebra-based Physics 1 . Bolded effect size values indicate statistically significant differences at the level of $p<0.05$.

\begin{tabular}{|r|c|c|c|}
\hline Calculus-based physics & $\mathbf{F}(\mathrm{N}=144)$ & $\mathbf{M}(\mathrm{N}=323)$ & $\mathbf{d}$ \\
\hline Self-efficacy & 2.55 & 2.89 & $\mathbf{0 . 7 5}$ \\
\hline Fascination & 2.96 & 3.17 & $\mathbf{0 . 3 7}$ \\
\hline Value & 2.71 & 2.85 & $\mathbf{0 . 3 2}$ \\
\hline Physics intelligence mindset & 2.95 & 3.09 & 0.22 \\
\hline Physics epistemology & 2.80 & 2.82 & 0.05 \\
\hline General intelligence mindset & 3.08 & 3.02 & -0.09 \\
\hline Grit & 3.54 & 3.42 & -0.17 \\
\hline Algebra-based physics & $\mathbf{F ~}(\mathrm{N}=270)$ & $\mathbf{M}(\mathrm{N}=151)$ & $\mathbf{d}$ \\
\hline Self-efficacy & 2.43 & 2.73 & $\mathbf{0 . 6 3}$ \\
\hline Fascination & 2.73 & 3.07 & $\mathbf{0 . 6 0}$ \\
\hline Value & 2.64 & 2.73 & 0.20 \\
\hline Physics intelligence mindset & 3.08 & 3.20 & 0.20 \\
\hline Physics epistemology & 2.75 & 2.76 & 0.02 \\
\hline General intelligence mindset & 3.08 & 3.05 & -0.04 \\
\hline Grit & 3.72 & 3.59 & $\mathbf{- 0 . 2 6}$ \\
\hline & & &
\end{tabular}

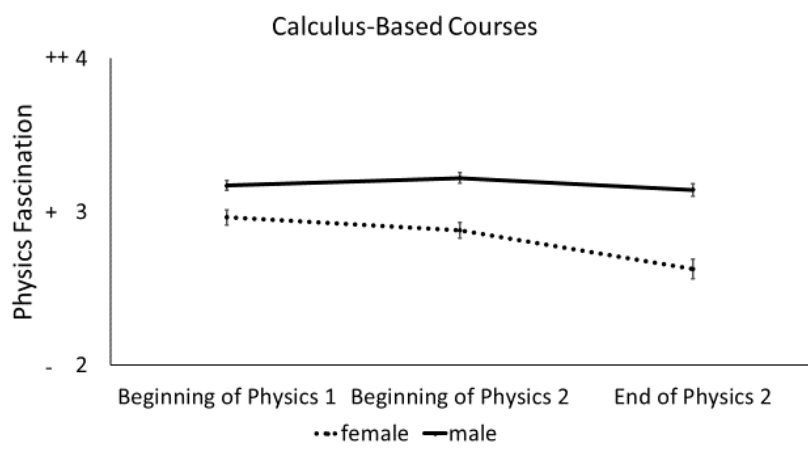

FIG 1. Students' average fascination with physics in an introductory, calculus-based physics sequence. "+"'and "-" signs indicate positive and negative responses, respectively.

fascination with physics decreased significantly more than males' after taking a calculus-based Physics 1 course $(F(1$, $280)=5.69, p=0.018)$. That is, the gap between male and female students' reported fascination increased. Figure 1 shows the change in male and female students' fascination after taking a calculus-based Physics 1 course.

Furthermore, we examined how students' motivational characteristics changed after taking a Physics 2 course focusing on electricity and magnetism. We found that, on average, the gaps between male and female students' motivational characteristics remained approximately the same after taking a Physics 2 course. However, we did find that females' average fascination decreased significantly more than males $(F(1,246)=6.41, p=0.012)$ after taking a calculus-based Physics 2 course. Furthermore, females' value associated with physics decreased significantly more than males' in calculus-based Physics $2(F(1,246)=5.64$, $p=0.018)$. In other words, the gap between female and male students' reported fascination and value associated with 
physics increased after taking a calculus-based Physics 2 course. See Figure 1 for the change in male and female students' fascination and Figure 2 for the change in male and female students' value associated with physics after taking a calculus-based physics 2 course.

In addition, we found that females' reported physics intelligence mindset became more "fixed" relative to males and the gap between female and male students' physics intelligence mindset increased after taking an algebra-based Physics 2 course $(F(1,278)=5.359, p=0.021)$. Figure 3 shows the change in male and female students' physics intelligence mindset after taking an algebra-based physics 2 course.

\section{DISCUSSION}

We found that at the beginning of a Physics 1 course, female students' average self-efficacy, fascination, and value associated with physics were significantly lower than males'. We also found that females' fascination and value associated with physics decreased significantly more than males' after taking a calculus-based physics course sequence. Furthermore, after taking an algebra-based physics 2 course, females' physics intelligence mindset became more "fixed" as compared to males' physics intelligence mindset. We found that grit was the only construct on which females reported average scores significantly higher than males.

Our future work will focus on how the motivational characteristics discussed here relate to the type of instruction (e.g., flipped vs. traditional lecture courses), students' prior knowledge, and learning over time in physics courses. While the observed differences in female and male students' motivation may contribute to differences in their learning outcomes, it is possible that students' motivation may also be affected differently by different types of instruction, their prior knowledge, and their learning outcomes. For example, a student's overall performance throughout a physics course sequence may impact his/her intelligence mindset. On the other hand, a student's intelligence mindset may also impact his/her overall performance in a course. These results also raise questions about whether there are potential gender biases at play in the classrooms that function towards marginalizing women. Future work can examine the causal links between these different factors, i.e., students' motivation, learning outcomes over time, type of instruction, and psychological messaging in the classroom or school.

[1] https://www.nsf.gov/statistics/2017/nsf17310/data.cfm

[2] V. Coletta, J. Phillips, J. Steinert,AIP. Conf. Proc. (AIP, 2012).

[3] D. Meltzer, Am. J. Phys. 80 (2012).

[4] A. Cavallo, W. Potter, M. Rozman, School Sci. and Math. 104, 2004.

[5] M. Wang, and J. Degol, Dev. Rev. 33 (2013).

[6] V. Sawtelle, E. Brewe, L. Kramer, J. Res. Sci. Teach. 49 (2012).

[7] A. Duckworth and P. Quinn, J. Per. Assess. 91 (2009).

[8] C. Dweck (Ballentine, New York, 2006).

[9] D. Hammer, Cognition Instruct. 12 (1994).

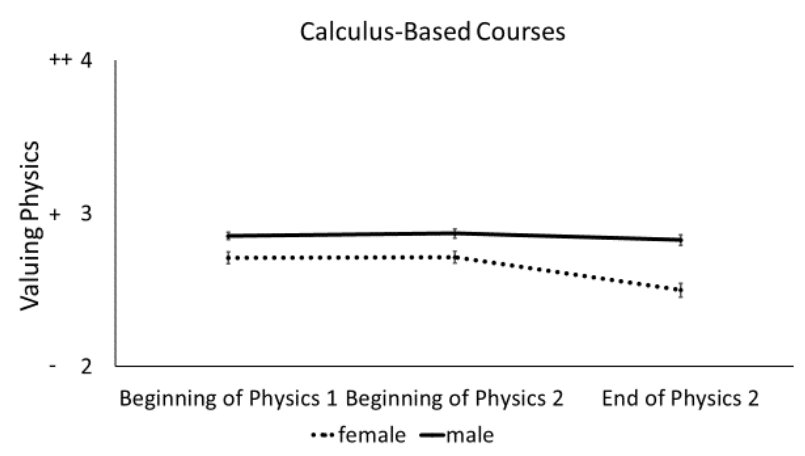

FIG 2. Students' average value associated with physics in an introductory, calculus-based physics sequence.

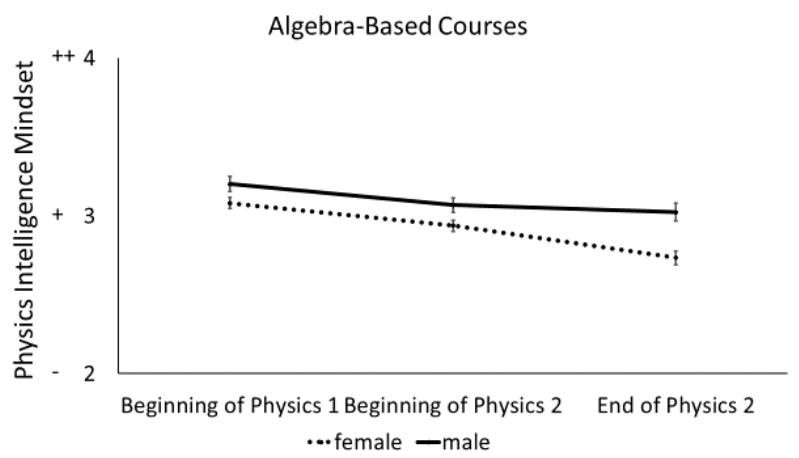

FIG 3. Students' average physics intelligence mindset in an introductory, algebra-based physics sequence.

Instructors, researchers, and curriculum developers in physics can use these findings to develop and implement effective approaches and learning tools, in part, by taking into account students' motivational characteristics. Focusing on students' motivational characteristics, especially those of female students, may prove fruitful in decreasing the gender gap, helping more women succeed in physics courses, and increasing the diversity in physics-related fields.

\section{ACKNOWLEDGEMENTS}

This work was supported by Grant DUE-1524575 from the National Science Foundation and Grant 22020483 from the James S. McDonnell Foundation.

[10] E. Redish, J. Saul, R. Steinberg, Am. J. Phys. 66 (1998).

[11] B. Zwickl, T. Hirokawa, N. Finkelstein, H. Lewandowski, PRST-PER 10 (2014).

[12] http://www.activationlab.org/tools/

[13] K. Miller, J. Schell, A. Ho, B. Lukoff, E. Mazur, PRST-PER 11 (2015).

[14] S. Glynn, P. Brickman, N. Armstron, G. Taasoobshirazi, J. Res. Sci. Teach. 48 (2011).

[15] E. Marshman, Z. Kalender, C. Schunn, T. Nokes-Malach, C. Singh, Can. J. Phys. (2017) doi: http://dx.doi.org/10.1139/cjp2017-0185. 